EESTI NSV TEADUSTE AKADEEMIA TOIMETISED. XVII KOIDE

KEEMIA - GEOLOOGIA. 1968, Nr. 1

ИЗВЕСТИЯ АКАДЕМИИ НАУК ЭСТОНСКОН ССР. ТОМ ХVII

Химня * ГЕолоГИя. 1968, Ni 1

\title{
НЕКОТОРЫЕ ВОПРОСЫ РАЗВИТИЯ НАУКИ И ТЕХНИКИ В ОБЛАСТИ ДОБЫЧИ И ИСПОЛЬЗОВАНИЯ ПРИБАЛТИИСКОГО СЛАНЦА-КУКЕРСИТА
}

Горючий сланец-кукерсит, одно из основных природных богатств Северо-Западного района страны, уже на протяжении примерно полувека находит все более широкое применение в энергетике и в качестве источника для получения облагороженных топлив и химического сырья. Накопленный в этой области богатый опыт нуждается в научной систематизащии и обобщении.

Нанболыший интерес представляют следующие вопросы, еще недостаточно освещенные в соответствующей литературе: характер и динамика развития науки о сланце и технике его добычи, переработки и использования; их взаимосвязь в разные исторические периоды становления и разработки проблемы; интенсивность разработки отдельных направлений, отражающая изменения не только политической и экономической ситуации, но и уровня развития науки и техники в целом, влияния новых тенденций в области использования горючих ископаемых.

Объективный и достоверный ответ на эти и многие другие вопросы можно получить на основе научно-статистического анализа многочисленных публикаций по проблеме, чнсло которых к настоящему времени превышает шесть тысяч. В настоящем сообщенни приведены некоторые результаты первого этапа такой работы на базе собранных автором библиографических материалов. Последние включают все виды публикаций o прибалтийском сланце - монографии, статьи, авгорефераты, тезисы докладов, а также законы, постановления, инструкции, материалы конференций, сессий, совещаний и т. п. К ним отнесены и работы, в которых ннтересующая нас проблема затронута частично.

Сбор материалов не ограничивался с точки зрения языка, а также территории, на котором и где та или иная работа была опубликована.

В процессе сбора материалов проработано 17 библиотечных каталогов, просмютрено 75 периодических изданий. Всего установлено 6828 источников, опубликованных по 1965 г. включительно. Автор пользуется случаем принести благодарность владельцам личных картотек, в первую очередь профессору А. Аарна и кандидату технических наук Н. Серебрянникову за любезное их предоставление, профессору М. Губергрицу и кандидату исторических наук О. Қарма - за руководетво при обработке и систематизации материалов. Количество неустановленных материалов, судя по результатам проверок, не превышает $1-2 \%$ от общего числа публикаций, что не может отразиться на статистнческой достоверности предпринятой работы.

Собранный материал систематизирован по 17 основным направлениям (см. таблицу), которые условно разбиты на ряд частных тематических разделов - всего 109. Представленные статистические мате- 


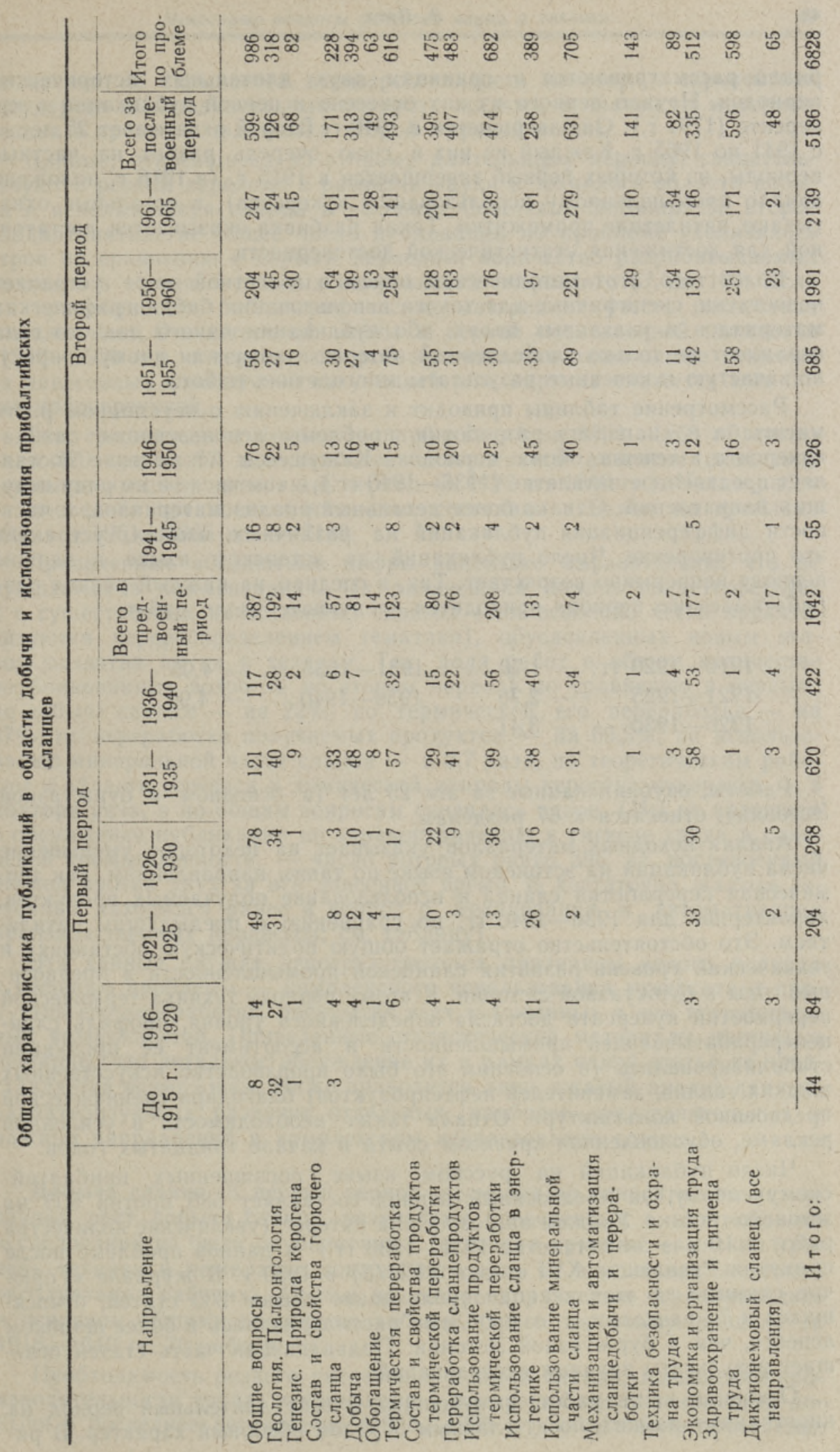


риалы рассматриваются в границах двух длительных исторических периодов. Начало первого из них отнесено к первой публикации о кукерсите (1791 г.). Он завершается в 1940 г. Второй охватывает 25 лет с 1941 по 1965 г. Каждый из них в свою очередь разбит на частные периоды, из которых первый завершается в 1915 г. (в 1916 г. положено начало промышленному использованию кукерсита), а остальные охватывают пятилетние промежутки. Такая разбивка оказывается достаточной для достижения статистической достоверности.

Более того, этот методический прием в известной мере устраняет недостатки, специфичные для такого использования библиографических материалов в указанных целях, ибо публикации одного данного года отражают не только злободневный интерес к тому или иному вопросу, но зачастую и конечные результаты многолетних работ.

Рассмотрение таблицы приводит к заключению о неуклонном росте масштаба и днапазона разработки проблемы использования сланцакукерсита в течение обоих периодов. Кажущееся исключение составляет предвоенное пятилетие (1936-1940 гг.), в том числе и по ряду ведущих направлений. Однако более детальный анализ материалов, в частности дифференциация публикаций на различных языках, устраняет это противоречие. Число публикаций на эстонском языке в первом периоде непрерывно возрастает. Так, в среднем на каждый раздел разрабатываемого периода приходится следующее число работ:

$\begin{array}{lll}1916-1920 \text { гг. }-1,70 & 1931-1935 \text { гг. }-4,05 \\ 1921-1925 & -2,76 & 1936-1940 \\ 1926-1930 & -3,41\end{array}$

Работы, опубликованные за эти 25 лет (в основном в буржуазной Эстонии), относятся к 67 разделам.

Анализ исходных материалов указывает на некоторое уменьшение числа публикаций на эстонском языке по таким направлениям, как термическая переработка сланца и использование получаемых продуктов, характерное для 1936-1940 гг. по сравнению с. предыдущим пятилетием. Это обстоятельство отражает общую политическую обстановку и технический уровень развития сланцевой промышленности в предвоенные годы в буржуазной Эстонии. К этому периоду техника термической переработки кукерсита достигла определенного уровня, профиль сланцеперерабатывающей промышленности и ассортимент ее продукции стабилизировались (в основном это было производство искусственных жидких топлив, заменителей нефтепродуктов) благодаря специфической предвоенной конъюнктуре. Отпала также необходимость в усиленной рекламе, обусловленная кризисом сбыта в начале тридцатых годов.

Число публикаций на русском языке, посвященных прибалтийскому сланцу, за предвоенный период составляет 585 против 605 на эстонском языке. Укажем на возросший интерес (увеличение количества работ в 10 раз за пятилетие 1931 - 1936 гг.) к данной проблеме после принятия Резолюции XVI съезда ВКП(б) в 1930 г. В журнале «Горючие сланцы» за этот период опубликовано свыше 200 статей, относящихся к 75 разделам, т. е. проблема рассматривалась в более широком аспекте, чем в буржуазной Эстонии. Подавляющая часть статей освещает результаты научных исследований.

Основная часть работ, выпущенных в этот длительный период на нностранных языках, носит главным образом обзорный характер. В ря- 
де из них не скрывается заинтересованность некоторых европейских государств в дополнительных ресурсах жидких, в частности моторных топлив в процессе подготовки второй мировой войны.

Данные, относящиеся ко второму длительному периоду, свидетельствуют о резком переломе в развитии науки и техники в области добычи и использования сланца в условиях Советской Эстонии. За второе двадцатипятилетие общее число публикаций по проблеме увеличилось втрое по сравнению с первым периодом, количество разрабатываемых разделов в составе основных направлений возросло с 67 до 109. Если же при обработке библиографических материалов учесть показатели тяжелых лет Отечественной войны и первой послевоенной пятилетки (1946-1950 гг.), в течение которой залечивались лишь самые тяжелые из нанесенных фашистской оккупацией ран, картина окажется еще более красноречивой.

Так, среднегодовое количество публикаций за 1951-1965 гг. составило 320 против 87 для наиболее интенсивного развития сланцевой промышленности в довоенный период (с 1926 по 1940 гг.). Число работ за последнее предвоенное пятилетие составило в целом по проблеме 422 , а в $1961-1965$ гг. - 2139.

Приведенные абсолютные цифры настолько выразительны, что не нуждаются в комментариях. Их дальнейший анализ свидетельствует и о существенных качественных сдвигах (они особенно четко характеризуются перераспределением тематики), обусловленных новым этапом развития науки и техники. Так, доля работ в общем количестве опубликованных возросла во втором периоде по сравнению с первым: по добыче сланца - на $22 \%$, по термической его переработке - на $27 \%$, по переработке получаемых продуктов - на $69,5 \%$, по использованию минеральной части сланца - в 2,7 раза, по теоретическим работам в области генезиса и химической природы керогена кукерсита - в полтора раза, а по общим вопросам снизилась вдвое. (Мы не включаем в обсуждение публикации по здравоохранению и гигиене труда в сланцевой промышленности, - число которых равно 596 з2 послевоенный период против двух за все довоенное время. В достаточно жалком состоянии находился ранее и вопрос о механизации и автоматизации производственных процессов; см. таблицу).

Эти данные служат непосредственным признаком нового подхода к решению проблемы - комплексного использования кукерсита и продуктов его переработки, раскрытия всех заложенных в нем потенциальных возможностей. Приведенные статистические материалы настолько обширны, что детальное обсуждение их в рамках одной статьи не представляется возможным. Ниже приводится лишь сжатый анализ данных, характеризующих развитие отдельных, наиболее представительных и важных направлений в комплексном использовании сланца.

Добыча сланца. В первый период, несмотря на относительно интенсивный рост добычи сланца, результаты проведенных в этой области исследований не были опубликованы (основная причина - низкий уровень техники и нежелание совершенствовать ее в условиях жестокой эксплуатации рабочих). Статьи по этому направлению ограничивались в основном общими вопросами добычи (всего по этому разделу за 1916 - 1940 гг. 70 работ).

Необходимость резкого увеличения добычи сланца, повышения производительности труда, механизации и внедрения новой технологии добычи в последнее десятилетие (1956-1965 гг.) обусловила проведение 
ряда исследований и опытных работ, усиление обмена передовым техническим опытом. В этой области в 1956-1960 гг. опубликовано 65 работ, в последующее пятилетие - 128. Прирост публикаций, косвенно отражающих состояние развития исследований, составил таким обраsом 97\%. За тот же период объем добычи сланца возрос на $75 \%$. Посколіьку отражаемая в публикациях исследовательская работа предшествует и сопутствует практическому освоению, то настоящий пример отчетливо свидетельствует о достаточно высокой народнохозяйственной эффективности проведенных научно-технических разработок.

Использование сланца в энергетике. Одним из основных разделов этого направления является разработка и совершенствование техники сжигания кукерсита (всего, начиная с 1921 г., 104 публикации, из них в первый период - 18, в том числе 7 на эстонском и 11 на русском языке). Публикация работ этого раздела резко возрастает в послевоенные годы, что отражает мощное развитие «сланцевой» энергетики в Советской Эстонии. Так, к 1946-1950 гг. относится 14 наименований, к $1951-1955$ гг. $-17,1956-1960-27$ и 1961-1965 гг. - 28.

Примерно на этом же уровне (94 работы) находится и разработка раздела, связанного с конструкцией и переоборудованием топок в энергоагрегатах, работающих на сланце (35 - в довоенный период, 59 за $1946--1965$ гг.).

Принципиально новым разделом (он отнесен нами к энергетике) является энерготехнологическое, или энергохимическое, использование сланца, отражающее современную тенденцию к сочетанию энергетики и химии на базе сланца, т. е. комплексному решению всей проблемы. C 1949 по 1965 г. в этой области было опубликовано 20 работ, посвященных принципиальному обсуждению вопроса. Если учесть, что ряд публикаций отнесен к другому направлению (термическая переработка сланца, в частности с твердым теплоносителем, как техническая основа энергохимии), станет ясным интерес к такой перспективной постановке вопроса.

Термическая переработка сланца. Разработка этого направления, одного из ведущих в составе проблемы, отражена всего в 616 публикациях, из которых около $20 \%$ относятся к довоеннному периоду. Значительная часть последних (72) вышла в свет на русском языке и посвящена главным образом результатам научных нсследований. На эстонском языке за этот же период опубликовано всего 13 работ (из них 7 статей по теории термического разложения кукерсита *) и на иностранных языках 39 сообщений, в основном обзорного характера.

Судя по небольшому числу публикаций (3), вопросам дальнейшей разработки новых систем для термнческой переработки сланца в буржуазной Эстонии уделялось лишь незначительное внимание. Это объясняется как изложенными выше причинами, так и неопределенностью перспектив последующего развития промышленности переработки кукерсита.

Завершению первого этапа послевоенного восстановления промышленности и созданию новой ее отрасли - газосланцевой (1946-1950 гг.) сопутствует резкий рост числа публикаций: в 1951-1955 гг. -75 , в следующем пятилетии - 254. Известное снижение - до 141 с 1961 по

* Это направление частично освещено и в сообщениях общего характера, отнесенных нами к первому направлению (см. таблицу). 
1965 г. - свидетельствует прежде всего об успещном завершении основных работ по совершенствованию технологии и модернизации сланцеперерабатывающих агрегатов генераторов повышенной производительности, камерных и туннельных печей.

Постараемся на наглядном примере показать, в какой мере отмеченное интенсивное развитие работ по термической переработке сланца оказалось подготовленным в итоге проведенных научных исследований. Так, в целом по разделу «Теория термического разложения сланца» число публикаций составляет 153. Из них на промежуток с 1951 по 1955 г. приходится 21 работа, или $28 \%$ всех работ по данному награвлению за то же время. За последующее пятилетие (1956-1960 гг.) по разделу опубликовано 56 сообщений. Всего на эти десять лет приходится около половины всех опубликованных работ по вопросам теории.

По разделу же, посвященному совершенствованию систем термической переработки кукерсита, за 1951-1955 гт. вышло в свет 16 публикаций, а в следующем пятилетии - 103, или более половины всех известных нам работ.

Таким образом, теоретический задел, созданный исследованиями 1951 - 1955 гг., получил непосредственную практическую реализацию в 1956-1960 гг. Укажем на особенно большое число работ, выполненных по освоению технологии, повышению производительности и модернизации шахтных генераторов (70 из 194 в целом по разделу) -- одному из наиболее сложных вопросов в области техники переработки сланца.

Дальнейшее развитие теории и экспериментальных исследований в стенах научных учреждений, вузов и заводских лабораторий, как это видно из приводимых ниже данных, обеспечило не только продолжение работ по совершенствованию существующей технологии и аппаратуры. Оно было в большой мере направлено на поиск, создание и разработку новых, более прогрессивных методов термической переработки сланца, соответствующих современным тенденциям комплексного использования топлив и получения более высококачественного химического сырья. Так за 1956-1960 гг. в печати появилось 13 сообщений о разработке метода переработки сланца с твердым теплоносителем, а в 1961 1965 гг. - 28 работ, связанных с опытной проработкой и освоением этого метода.

Использование продуктов термической переработки сланца. Из 682 работ по этому разделу до 1940 г. опубликовано 208, а с 1946 по 1965 г. - 474, причем только за два последних пятилетия - соответственно 176 и 239. Әто свидетельствует о возрастающем значении, которое придается в Советской Эстонии рациональному использованию сланцевых продуктов.

Особенно важна при анализе указанных материалов дифференциашия принципиальных путей использования этих продуктов - без дальнейшей химической переработки (группа А) и с применением в качестве химического сырья (группа Б). До 1940 г. подавляющее число публикаций (189) относится к первой группе и лишь $19-$ ко второй. Это соотношение резко меняется в послевоенный период. Всего за 1946 1965 гг. по группе А нами зафиксировано 225 источников, по группе Б - 249, то есть в 13 раз больше, чем за все довоенное двадцатипятилетие.

В десятилетие 1946-1955 гг. количество публикаций по вопросам химического использования сланцепродуктов составило всего 13 (почти 
столько же, сколько за весь довоенный период), в 1956-1960 гг. - 86 и в последнем пятилетии - 147. Около $45 \%$ опубликованных за эти годы работ группы Б посвящены использованию сланцевых фенолов. В послевоенные годы тематика работ этой группы существенно обновляется и расширяется. Сюда входят исследования и опытные работы по синтезу поверхностно-активных веществ, флотореагентов, клеев, дубителей, смазочных масел, пестицидов, применению ароматических углеводородов (на базе жидких сланцепродуктов), синтезу азотных удобрений, получению серы и продуктов ее переработки, использованию газообразных олефинов для получения полимеров, пластических масс и т. д. (на основе сланцевых газов).

Таким образом, принципиальная установка на максимальную химизацию сланцеперерабатываюшей промышленности, на комплексное и рациональное использование природных богатств страны получает в Советской Әстонии практическое претворение в жизнь.
Институт химии и Научная библиотека Академии наук Эстонской ССР
Поступила в редакцию 4/IX 1967

\section{E. PATA}

\section{MONINGAID TEADUSE JA TEHNIKA ARENEMISE KUSIMUSI KUKERSIIDI TOOTMISE JA KASUTAMISE ALAL}

Artiklis käsitletakse teaduse ja tehnika arenemise küsimusi Eesti NSV põlevkivitöōstuses, lähtudes sellest, et probleemide aktuaalsus on vahetult seotud avaldatud tööde arvuga.

Uurimistōō materjalina on kasutatud autori poolt koostatud bibliograafilist kartoteeki teemal \&Eesti põlevkivi». Esitatakse bibliograafia koostamise printsiibid. Kogutud materjal, 6828 nimetust, on liigitatud 17 uurimissuunaks (vt. tabel).

Artiklis analüüsitakse teaduse ja tehnika arenemist Eesti pôlevkivitööstuses ühelt poolt kahel pikemal perioodil (kuni 1940. aastani ja aastail 1941-1965) ja teiselt poolt viisaastakute kaupa üksikutes olulisemates arenemissuundades (pōlevkivi tootmine, energeetiliseks otstarbeks kasutamine, termiline töötlemine ja produktide kasutamine). Näidatakse pōlevkivitööstuse arengut kodanlikus ja Nõukogude Eestis ning teaduse osa pōlevkivi töötlemise arendamises.

\section{E. PATA}

\section{GEDANKEN ZUR ENTWICKLUNG DER WISSENSCHAFT UND TECHNIK AUF DEM GEBIET DER GEWINNUNG UND NUTZUNG DES BALTISCHEN OLSCHIEFERS KUKERSIT}

Im Artikel wird die Frage der Entwicklung der Wissenschaft und Technik auf dem Gebiet der estnischen Olschieferindustrie behandelt, unter Zugrundelegung des Sachverhalts, da $B$ die Aktualität dieses Problems in den erschienenen Veröffentlichungen unmittelbar zutage tritt.

Als Material für die Untersuchung diente die vom Verfasser zusammengestellte bibliographische Kartothek zum Thema «Der estnische Ölschiefer». Im Artikel werden auch die bei der Zusammenstellung der Bibliographie geltenden Zeitgedanken dargelegt. Das erfabte Material - insgesamt 6828 Benennungen - ist im Anklang an die Unterschiedlichkeit der Forschungszweige nach 17 Richtungen hin aufgeteilt (siehe Tabelle).

Der Artikel bringt eine Analyse des Gesamtbildes der Entwicklung der Wissenschaft und Technik auf dem erwähnten Gebiet im Laufe von zwei historisch bedingten Zeitabschnitten, d. h. bis 1940 und von 1941 bis 1965. Innerhalb dieser Zeitabschnitte wurde eine Gliederung nach Fünfjahrabschnitten und erstrangigen Forschungsgebieten (Ölschiefergewinnung, energetische Nutzung, thermische Verarbeitung, Olschieterprodukt u. s. w.) zweckbestimmt durchgeführt. Im Rahmen des Gesamthildes de: Entwicklung der Ölschieferindustrie im bürgerlichen Estland und in der Estnischen Sowjetrepublik wird der Anteil der wissenschaftlichen Forschung am technischen Fortschritt bei der Nutzung des Olschiefers hervorgehoben. 